\title{
Symptoms of the musculoskeletal system and exposure to magnetic fields in an aluminium plant
}

\author{
Bente E Moen, Per Arne Drabløs, Svein Pedersen, Malvin Sjøen, Georg Thommesen
}

\begin{abstract}
Objective-The study was performed to examine the influence of the exposure to magnetic fields in the potrooms of an electrolysis plant on the occurrence of musculoskeletal symptoms among the employees. The study was performed after much discussion and worry in the aluminium industry about this issue.

Methods-A retrospective cohort study was performed at an aluminium plant. The occurrence of musculoskeletal symptoms registered at health controls performed by the occupational health care unit in 1986 and 1991 was assessed from employees exposed to magnetic fields in the potrooms $(n=342)$ and from a control group $(n=277)$. The data were collected before the discussion about the effects of magnetic fields started. The exposure to static magnetic fields was found to be 3-20 $\mathrm{mT}$ inside the potrooms. Ripple components (alternating currents (AC fields)) were registered as well.

Results-No difference between the exposed and unexposed groups was found for the reported musculoskeletal symptoms in 1986 or in 1991.

Conclusions-There seems to be no relation between work in potrooms with exposure to static magnetic fields and the occurrence of musculoskeletal symptoms.
\end{abstract}

(Occup Environ Med 1995;52:524-527)

Institute of

Occupational

Medicine, University

of Bergen, Ulriksdal

8C, N-5009 Bergen,

Norway

Bente E Moen

Norsk Hydro Karmøy

Fabrikker, N-4265

Håvik, Norway

Per Arne Drabløs

Svein Pedersen

Malvin Sjøen

Norwegian Radiation Protection Authority, Box 55, N-1345 Østerás, Norway Georg Thommesen

Correspondence to:

Dr Bente E Moen, Institute of Occupational Medicine,

University of Bergen,

Ulriksdal 8C, N-5009

Bergen, Norway.

Accepted 27 April 1995
Keywords: static magnetic field; musculoskeletal symptom; potroom

Effects on human skeletal muscle during occupational exposure to magnetic fields are in general not well known. Skeletal muscle is known to contract when exposed to intense acute magnetic pulses, ${ }^{1}$ but effects on skeletal muscle caused by less intense exposure to magnetic fields are not clear. Several experimental studies of the effects of static magnetic fields on nerve function have been performed, but the results are conflicting. ${ }^{23}$ Some studies suggest that static magnetic fields increase the exitability of the motor nerves. ${ }^{45}$ It has also been suggested that magnetic fields may have an activating effect on synaptic transmission in smooth and skeletal muscle. ${ }^{6}$ Magnetic fields have also been shown to induce various alterations of tissue metabolism, including reduction of glycogen content in nerve and muscle cells. ${ }^{7}$ Small variations in static magnetic fields $(10 \mathrm{~T})$ are sufficient to alter the rate of myosin phosphorylation in a cell free preparation. ${ }^{8}$

Whether magnetic fields have adverse effects or not on the human musculoskeletal system is not clear. Magnetic fields are in fact suggested to have therapeutic applications related to the musculoskeletal system..$^{9} 10$ They are for instance used to promote healing of fractures and wounds by orthopaedic surgeons. These effects are not generally acknowledged. Epidemiological studies of the effects of static magnetic fields on the occurrence of musculoskeletal disorders are not known. Several studies have examined the general health effects related to occupational exposure to magnetic fields.

Russian studies describe headache and other symptoms of the nervous system among workers exposed to electric and magnetic fields. ${ }^{11}{ }^{12}$ Such symptoms may arise from disorders in the musculoskeletal system. Comparable health surveys on occupationally exposed workers in other countries have failed to confirm similar effects, ${ }^{13-17}$ with the exception of a small Spanish study. ${ }^{18}$ Studies have also been performed to investigate health effects of this kind among populations that live near high voltage transmission lines. The results are contradictory and the conclusions uncertain. ${ }^{19-21}$ None of these studies have examined the occurrence of other symptoms that may be related to effects on muscles. A Swedish study suggested a relation between motor neurone disease and employment in electrical occupations. These workers were also exposed to different chemical agents and their exposure to magnetic fields was not well described. ${ }^{22}$ In Norway, exposure to magnetic fields has been suggested as a possible cause of musculoskeletal disorders in workers. ${ }^{23}$ The issue, this time related to work in potrooms, was raised as a major discussion in Norway in 1991-2, and has focused explicitly on musculoskeletal disorders among workers exposed to static magnetic fields. Our present study was performed to see whether occupational exposure to magnetic fields in potrooms influences the occurrence of musculoskeletal symptoms.

\section{Subjects and methods} SUBJECTS

A retrospective cohort study was performed at an aluminium plant. The production of 
aluminium at this plant takes place by an electrolytic process. Some of the employees are regularly exposed to high magnetic fields during work in the potrooms. The occupational health care unit at the plant had registered health data about the employees systematically for several years. These data were stored in computer files from 1986, making a retrospective study from this year possible. The study period was set at 1986 to 1991 . After 1991, a public discussion about the possible effects of magnetic fields in electrolysis plants on the musculoskeletal system was raised in Norwegian newspapers and television. As this discussion may have biased any information obtained about this issue, the study period ends before this discussion started. A cohort of exposed and unexposed workers was chosen retrospectivly among the workers employed in 1986. The cohort was closed and no new employees were included after the initial selection of the study base. If any of the employees ended their work at the plant or changed work site, they were removed from the cohort.

All workers in the plant were in a schedule of regular health controls at the occupational health care unit. The workers were examined at different intervals. Hardly any employees refused to participate in these health controls. At the health control the employees answered a questionnaire about their health and were examined by a medical doctor. Workers from the potrooms, the cast house, and the rolling mill, and all transport workers who had participated in a health control in 1986 were chosen as the study base. The employees from the potrooms were exposed to magnetic fields during their work, whereas the other groups of workers were not. The unexposed workers had a similar type of work to those in the potrooms in terms of physical exertion, and they had a similar social level.

\section{EXPOSURE TO MAGNETIC FIELDS}

Two different types of potrooms existed in the plant; potrooms with open Söderberg pots, and potrooms with hooded pots and prebaked anodes. The magnetic fields in electrolysis potrooms are mainly due to reduction in direct electric current (DC). The DC is produced by rectifying three phase $50 \mathrm{~Hz}$ current. It therefore contains remnants of the original alternating current (AC), usually referred to as "ripple".

The magnetic field recordings were performed at two sessions during the autumn of 1991 as part of a national survey. ${ }^{24}$ The working environment in the pot rooms had not been changed in the period from 1986 until the recordings were made in 1991. The DC component (the static magnetic field) was measured by means of temperature compensated Hall effect chips (Honeywell), the output voltage of which was read on a digital multimeter. The workers in the potrooms were regularly exposed to estimated average static magnetic fields of the order of magnitude of $3-10 \mathrm{mT}$. Parts of the body could occasionally be exposed up to about $50 \mathrm{mT}$ - for example, when the workers warmed their backs on the risers during a chilly watch. The AC components, the ripple fields, were picked up by a one dimensional search coil that had an effective area of $1 \mathrm{~m}^{2}$, producing an induced voltage numerically equal to the rate of change of the magnetic flux density ( $1 \mathrm{~V}$ represents $1 \mathrm{~T} / \mathrm{s}$ ). The signal from the coil was fed into a fast Fourier transformer (A\&D $3522,0-20 \mathrm{kHz}$ ), which could also be used as an oscilloscope. Significant frequency peaks of the ripple fields were multiples of $50 \mathrm{~Hz}$, particularly $100,200,300,600$, and $1200 \mathrm{~Hz}$. A $50 \mathrm{~Hz}$ component was found close to the rectifier in the Söderberg potroom, presumably due to ordinary power cables running parallel to the junctions. Above $1200 \mathrm{~Hz}$ there were only minor frequency peaks. The ripple amplitude (peak value) amounted to 7-8 $\mathrm{mT} / \mathrm{s}\left(\mathrm{V} / \mathrm{m}^{2}\right)$ close to the rectifiers. In the middle of potrooms, the ripple amplitude was about $0.3 \mathrm{mT} / \mathrm{s}$.

No survey of magnetic fields was performed in the workplaces of the participants in the control group in this plant. Measurements made in similar plants, however, indicate that the typical magnetic fields in these working areas are similar to the fields in any industrial workplace without any dominating source of magnetic fields. The fields produced by the potlines should be regarded as negligible, as the control group performed their work far from this area.

\section{HEALTH DATA}

At each health control, the employees answered a questionnaire about the occurrence of symptoms of the chest, the digestive system, the skin, sleep disorders, and smoking habits. These data were obtained for the study base at the time of inclusion in 1986. Age, height, and weight of each person were obtained as well. In 1986 the employees answered questions about the occurrence of symptoms (pain and discomfort) in the past year from the arms, neck, and shoulders as well as from the back, hips, and legs. In 1991 they were asked similar but more detailed questions about the occurrence of symptoms in the past year from the arms, neck, shoulders, elbows, wrists, hands, upper back, lower back, hips, knees, ankles, and feet. The questionnaires used were not standardised, but the questions used in 1991 were a part of a Nordic questionnaire. ${ }^{25}$

A statistical power analysis was performed on the occurrence of symptoms of the back. With a one year period prevalence of $30 \%$ and a significance level of 0.05 , we have a probability of $74 \%$ of detecting a $10 \%$ difference in the occurrence of symptoms, and a probability of $95 \%$ of detecting a $20 \%$ difference.

\section{STATISTICS}

The occurrence of the different variables in the exposed group and the control group was compared by $\chi^{2}$ tests for categorical variables and by the Student's $t$ test for continuous normally distributed variables. Age adjusted odds ratios of occurrence of musculoskeletal 
Table 1 Descriptive health data on a group of workers exposed to magnetic fields and a control group, obtained at a health examination at the time of inclusion in the study and five years later (the difference between the groups was tested by $\chi^{2}$ for categorical data and by Student's $t$ test for continuous data

\begin{tabular}{|c|c|c|c|c|c|c|}
\hline & \multicolumn{3}{|l|}{1986} & \multicolumn{3}{|l|}{1991} \\
\hline & $\begin{array}{l}\text { Exposed group } \\
(n=342)\end{array}$ & $\begin{array}{l}\text { Control group } \\
(n=277)\end{array}$ & $P$ value & $\begin{array}{l}\text { Exposed group } \\
(n=277)\end{array}$ & $\begin{array}{l}\text { Control group } \\
(n=222)\end{array}$ & $P$ value \\
\hline $\begin{array}{l}\text { Symptoms of the chest during the past year }(\mathrm{n}) \\
\text { Symptoms of the digestive system during the past year }(\mathrm{n}) \\
\text { Symptoms of the skin during the past year }(\mathrm{n}) \\
\text { Sleep disorders during the past year }(\mathrm{n}) \\
\text { Mean body weight }(\mathrm{kg}) \\
\text { Smokers }(\mathrm{n}) \\
\text { Mean consumption of tobacco (g/week) }\end{array}$ & $\begin{array}{r}35 \\
25 \\
64 \\
8 \\
75 \\
175 \\
770\end{array}$ & $\begin{array}{r}25 \\
32 \\
62 \\
15 \\
76 \\
102 \\
664\end{array}$ & $\begin{array}{l}0 \cdot 60 \\
0 \cdot 07 \\
0 \cdot 25 \\
0 \cdot 01 \\
0 \cdot 20 \\
0 \cdot 0004 \\
0 \cdot 01\end{array}$ & $\begin{array}{r}20 \\
15 \\
51 \\
26 \\
70 \\
135 \\
735\end{array}$ & $\begin{array}{r}14 \\
22 \\
60 \\
37 \\
80 \\
79 \\
551\end{array}$ & $\begin{array}{l}0 \cdot 60 \\
0.06 \\
0.05 \\
0.01 \\
0 \cdot 80 \\
0 \cdot 001 \\
0.007\end{array}$ \\
\hline
\end{tabular}

symptoms were calculated by the MantelHaenszel point estimate, dividing the workers into 10 year age groups. The MantelHaenszel $\chi^{2}$ formula was used to calculate the $95 \%$ confidence intervals (95\% CIs).

\section{Results}

At the time of inclusion in 1986, the exposed group consisted of 342 employees with a mean age of 42 years. The unexposed group consisted of 277 employees with a mean age of 47 years. At the end of the study, $20 \%$ of the employees in each group had left their work.

There was no difference between the groups for body weight or occurrence of symptoms of the chest, digestive system, or skin or of sleep disorders, neither at the start of the study period nor at the end of it (table 1).

The occurrence of smokers and the total tobacco consumed were significantly higher in the exposed group than in the unexposed group (table 1). Because of this difference, the occurrence of musculoskeletal symptoms in the group of smokers was compared with the occurrence of musculoskeletal symptoms in non-smokers. The comparison was performed by $\chi^{2}$ tests and by calculating age adjusted odds ratios. No significant differences in the occurrence of musculoskeletal symptoms were found.

There was a significant difference in the age of the exposed group and the control group, both at the time of inclusion ( $t$ test, $P=0.0001)$ and at the end of the study ( $t$ test, $P=0 \cdot 0001)$. Because of this, the analyses were adjusted for age by dividing the population in 10 year groups. The age adjusted

Table 2 Occurrence of symptoms of the neck, shoulders, elbows, wrists or hands, upper back, lower back, hips, knees, and ankles or feet the past year (1991) in a group of workers exposed to magnetic fields and a control group (the odds ratios have been age adjusted by dividing the workers into 10 year age groups: the Mantel-Haenszel point estimate was used).

\begin{tabular}{lll}
\hline Position of symptoms & $O R$ & $95 \% C I$ \\
\hline Neck & $0 \cdot 7$ & $0 \cdot 1-7 \cdot 5$ \\
Shoulders & $0 \cdot 7$ & $0 \cdot 2-7 \cdot 6$ \\
Elbows & $1 \cdot 3$ & $0 \cdot 4-8 \cdot 9$ \\
Wrists or hands & $1 \cdot 2$ & $0 \cdot 2-33 \cdot 0$ \\
Upper back & $0 \cdot 7$ & $0 \cdot 1-23 \cdot 0$ \\
Lower back & $1 \cdot 2$ & $0 \cdot 0-5 \cdot 0$ \\
Hips & $1 \cdot 2$ & $0 \cdot 1-34 \cdot 0$ \\
Knees & $0 \cdot 9$ & $0 \cdot 1-5 \cdot 8$ \\
Ankles or feet & $0 \cdot 7$ & $0 \cdot 1-10 \cdot 4$ \\
\hline
\end{tabular}

odds ratio for the occurrence of symptoms from the neck, shoulders, and arms in 1986 was $0.9(95 \% \mathrm{CI}=0.3-4.0)$, and from the back, hips, and legs the odds ratio in 1986 was $1 \cdot 1(95 \% \mathrm{CI}=0 \cdot 3-3 \cdot 2)$. Similar analyses were performed within the same cohort in 1991. No significant differences in the occurrence of musculoskeletal symptoms were found when the group exposed to magnetic fields was compared with the control group in 1991 (table 2).

\section{Discussion}

Our study shows no difference in the occurrence of musculoskeletal symptoms in workers exposed to static and time variable magnetic fields in the potrooms of an aluminium plant and a control group. This was found both at the beginning and the end of a five year period.

The occurrence of symptoms is a crude measure of the occurrence of musculoskeletal disorders. The workers may have minor problems of this kind that have not been registered. A higher occurrence of musculoskeletal symptoms would have been expected in the exposed group than in the control group during a follow up period of five years if the magnetic fields were of major importance in the aetiology of such symptoms. A standardised questionnaire was not used in the study, although the questions used in 1991 were a part of a Nordic questionnaire. The questions were not the same in 1986-7 as in 1991. This caused several limitations in the statistical analyses of the data. We were not able to evaluate any change in occurrence of symptoms within the different groups during the observation period because of this. This was the situation for both the exposed group and the control group, and should be of less importance in the comparison of these groups.

The subjects in the study base were selected for their exposure patterns only, not for their health. Also the data had been registered at the occupational health care unit before the study was designed, with no prior knowledge about the hypothesis of the study. The data had been registered in the years before the public discussion about this issue started in Norway. This makes the study base valid. Also, the data were exact and complete for all employees.

Confounding variables may have influuenced the results of our study. The exposed 
group and the control group were comparable, and worked in the same plant. The employees belonged to the same social level, and they had the same occurrence of several types of other health symptoms registered at the health control. Smoking seems to be a risk factor for musculoskeletal disorders. ${ }^{26} 27$ In our study, no difference was found between the occurrence of musculoskeletal symptoms among smokers and non-smokers. Also, the exposed workers smoked more than the control group. Increasing age is a risk factor for occurrence of musculoskeletal disorders. The occurrence of musculoskeletal disorders was adjusted for age in our study.

There is a possibility that a selection from the exposed group to the control group in the plant may have taken place before the study period started. If an employee cannot perform his work in the potroom-for example, for health reasons-he may be transferred to another work site in the plant. This may have introduced workers with a previous exposure to magnetic fields into the control group. The cohort design with no inclusion of new workers during the study period reduces the possible effect of this type of confounding.

\section{Conclusion}

No relation between the occurrence of musculoskeletal symptoms and occupational exposure to magnetic fields in potrooms was found in a five year cohort study. The results from this study must be interpreted with caution, as static magnetic fields constituted the main exposure. The results may be different for work with other types of exposure to magnetic fields.

1 Bücking J, Herbst $M$, Piontek P. The infiuence of a strong magnetic field on muscular contraction. Radiat Environ Biophys 1974;11:79-85.

2 Edelman A, Teulon J, Puchalska IB. Influence on the magnetic fields on frog sciatic nerve. Biochem Biophys Res Commun 1979;91:118-23.

3 Gaffey CT, Tenforde TS. Bioelectric properties of frog sciatic nerves during exposure to stationary magnetic fields. Radiat Environ Biophys 1983;22:61-73.

4 Hong C-Z, Harmon D, Yu J. Static magnetic field influence on rat tail nerve function. Arch Phys Med Rehabil 1986;67:746-9.

5 Hong C-Z. Static magnetic field infiuence on human nerve function. Arch Phys Med Rehabil 1987;68:162-4.

6 Davidovskaya TL, Khestanov SA. The influence of constant magnetic field on electrophsyiological properties of smooth and skeletal muscle and their neuromuscular connections [abstract]. European Bioelectromagnetics Assoc 2nd Congress
9-11 December. Bled, Slovenia: European Bioelectromagnetics Association, 1993:96.

7 Demetskii AM. Present views on the mechanism of curative effects of magnetic fields. Magnitologia 1991;1:6-11. (In Russian.)

8 Markov MS, Muehsam DJ, Pilla AA. Extreme sensitivity of cell-free myosin phosphorylation to ambient static field changes [abstract]. Bioelectric Repair and Growth Society Vol XIII, 13th Annual Meeting. Dana Point, CA: Bioelectric Repair in Growth Society, 1993:37.

9 Beers GJ. Biological effects of weak electromagnetic fields from $0 \mathrm{~Hz}$ to $200 \mathrm{MHz}$ : a survey of the literature with special emphasis on possible magnetic resonance effects. Magn Reson Imaging 1989;7:309-31.

10 Bruce GK, Howlett CR, Huckstep RL. Effect of a static magnetic field on fracture healing in a rabbit radius. Clin Orthop 1987;222:300-6.

11 Vyalov AM, Shpilberg PI, Yushkevish LB. To the question of static and variable magnetic field effects on human organism. In: Scientific transaction. Moscow: FF Erisman Hygiene Research Institute, 1964:169-75.

12 Asanova TP, Rakov AI. The state of health of persons working in the electric field of outdoor 400 and $500 \mathrm{kV}$ switchyards. IEEE Sci Publ 1966;10:4-5.

13 Malboysson E. Medical control of men working within electrical fields. Review of General Electricity 1976; (special issue): 75-80

14 Knave B, Gamberale F, Bergström S. Long-term exposure to electric fields: a cross-sectional epidemiological investigation of occupationally exposed workers in high-voltage substations. Scand $f$ Work Environ Health 1979; 5:115-25.

15 Broadbent DE, Broadbent MHP, Male JC, Jones MRL. Health of workers exposed to electric fields. $\mathrm{Br} \mathcal{F}$ Ind Med 1985;42:75-84.

16 Baroncelli P, Battisti S, Checucci A, Grandolfo M, Serio A, Vecchia P. A health examination of railway high-voltage substation workers exposed to ELF electromagnetic age substation workers exposed to 1 .
fields. $A m$ flnd $M e d$ 1986;10:45-55.

17 Gamberale F, Anshelm Olson B, Eneroth P, Lindh T, Wennberg A. Acute effects of ELF electromagnetic fields: a field study of linesmen working with $400 \mathrm{kV}$ power lines. Br F Ind Med 1989;46:729-37.

18 Fole FF, Dutrus E. Noeva aportacion al estudiode los campos electromagnéticos generadospor muy altas tensiones. Medicina y Seguridad del Trabajo 1974;22:15-8. (In Spanish.)

19 Dowson DI, Lewith GT, Campbell M, Mullee MA, Brewster LA. Overhead high-voltage cables and recurrent headache and depression. Practitioner 1988; 232:435-6.

20 Haysom C, Dowson D, Campbell MJ. The relevance of headaches and migraine in populations resident near overhead power lines-an epidemiological study. Complementary Medical Research 1990;4:12-5.

21 Haupt RC, Nolfi JR. The effects of high voltage transmission lines on the health of adjacent resident populations. Am $\mathcal{F}$ Publ Health 1984;74:76-8.

22 Gunnarson LG, Bodin L, Söderfeldt B, Axelson O. A case-control study of motor neurone disease: its relation to heritability and occupational exposures, particularly to heritability and occupational exposures,
to solvents. Br $\mathcal{F}$ Ind Med 1992;49:791-8.

23 Faye-Lund P. Muskelsmerter etter arbeid i magnetfelt. Norsk bedriflshelsegeneste. 1984;1:7-12.(In Norwegian.)

24 Thommesen, G, Bjølseth PS. Statiske og lavfrekvente magnetfelt $i$ norske smelte - og elektrolyseverk. Static and low frequency magnetic fields in Norwegian alloy and electrolysis plants. NRPA-report 1. Statens, Strålevern: Norwegian Radiation Protection Authority 1992:1. (In Norwegian.)

25 Kuorinka I, Jonsson B, Kilbom A, Vinterberg H, BieringSørensen F, Andersson G, Jørgensen K. Standardised Nordic questionnaires for the analysis of musculoskeletal symptoms. Applied Ergonomics 1987;18:233-7.

26 Parniapour M, Nordin M, Skovron ML, Frankel VH. Environmentally induced disorders of the musculoEnvironmentally induced disorders of the
skeletal system. Med Clin Am 1990;74:347-59.

27 Jones BH, Cowan DN, Tomlinson JP, Robinson JR, Polly DW, Frykman PN. Epidemiology of injuries associated with physical training among young men in the army. Med Sci Sports Exerc 1993;25:197-203. 